\title{
Ueber die natürliche Boraxsäure.
}

Die Boraxsäure wird jetzt in grofsen Mengen aus den Toskanischen Seen gewonnen, in Handel gebracht und gereinigt zu pharmaceut. Präparaten verwendet. Die ersten Sendungen, welche nach Frankreich gemacht wurden, bestanden aus 55 Boraxsäure, 34 Wasser, 10 bis 11 fremden Substanzen, unlösliche Stuffe, feruer Kali, Eisenoxyd, Ammoniak und Schwefelsäure.

Später wurde sie weniger rein geliefert und es traten darüber bedeutende Streitigkeiten ein. Die Käufer forderten eine Säure, die nur $10 \frac{0}{0}$ Unreinigkeiten enthalten sollte, die Lieferanten waren der Ansicht, sie könne selbst $20 \frac{0}{0}$ Unreinigkeiten enthalten, ohne dafs man sie als unrein betrachten küune. (!) Der darüber entstandene Streit, obgleich höchst einfach, wurde doch Gegenstand zahlreicher Kämpfe. Hr. Apotheker P a ul Villaresi, Secretair der med. Societait zu Livorno und Hr. Targioni Tozzetti, Professor der Chemie und Botanik zu Florenz, glaubten, dafs die Säure nicht als verkaufbar zu betrachten sei, wenn sie mehr als 11,75 $\frac{0}{0}$ fremde Materien (einschliefslich des Wassers) enthalte. Hr. Joseph Branchi, Professor der Chemie zu Pavia, Hr. Dr.Zanobi Lottini und Hr. Gaspard Mori in Livorno, halten eine Säure mit 20 und mehr Procenten Unreinigkeiten noch für gute Handelsware. Was hiervon $z u$ uriheilen, wird Jedermann einsehen, und für ein Product, das $20 \%$ und mehr Unreinigkeiten besitzt, nicht so viel bezahlen, als für das, was nur $10 \frac{\mathrm{g}}{0}$ Unreinigkeiten enthält. Man wird den Preis nach dem wahren Gehalt an Säure bestimmen.

\section{Apothekenverkauf.}

Eine mit einem Realprivilegium versehene Apothelse in der Provinz Magdeburg, in einer Stadt von 2000 Einwohnern, mit eirem Umsatz reines Medicinalgeschäft von 14- 1500 Rthlr., Nebengeschäft von 800 Rihlr. ist mit einer Anzahlung von 4500 Rthlr. zu 13,500 Rthlr. zu verkaufen. Näheres hierüber ertheilt

Lohburg, ohnweit Magdeburg, im Febr. 1839.

Hornemann, Apotheker. 